\title{
Improvement of catheter quality inspection process
}

\author{
Mariusz Bożek ${ }^{1}$, Agnieszka Kujawińska², Michat Rogalewicz ${ }^{2, *}$, Magdalena Diering ${ }^{2}$, \\ Pawet Gościniak $^{1}$ and Adam Hamrol ${ }^{2}$ \\ ${ }^{1}$ Aesculap Chifa Ltd., Poland \\ ${ }^{2}$ Poznan University of Technology, Chair of Management and Production Engineering, Poland
}

\begin{abstract}
Quality inspection is very often one of the most important stages of the production process, although it does not create any added value. Therefore, optimization of the related number of activities is of crucial importance. However, reduction should not be made arbitrarily, but preceded and documented by appropriate research. The article describes a study aimed at reducing the high cost of quality inspection as part of the manufacturing process of a diagnostic catheter at a medical company. The product is used for blood pressure monitoring and blood sampling by the Seldinger technique. A critical quality feature for the catheter is air/water tightness. Following a thorough analysis, some control points were eliminated, and others were improved. The resulting conclusion is that detection of defective components is the most beneficial for this specific production process if carried out during the 100 percent final quality inspection. The finding is based on the fact that the cost of producing the final device with a defective component is lower than a quality inspection run directly after each operation. The authors also managed to decrease the sample size for control charts used to supervise the adhesive connection strength.
\end{abstract}

\section{Introduction}

The key objective of a manufacturing process is the delivery of a product which meets customers' expectations. In practice, every manufacturing process is exposed to the effect of certain factors and obstacles which should be analysed and taken into consideration, but are difficult to be predicted at the stage of designing the process [1-4]. Such factors often cause non-compliance or defects in products, processes or equipment [5]. Undetected on an ongoing basis, non-compliant or defective semi-products are further processed or even reach the end user. In consequence, the manufacturer incurs additional costs related to repairs, claims, reduced efficiency or interruptions in the manufacturing process [6-7]. Therefore, proper assessment of the condition of the manufacturing process is important at the stage of designing the process.

\footnotetext{
${ }^{*}$ Corresponding author: michal.rogalewicz@put.poznan.pl
} 
The condition of a manufacturing process is assessed based on the data obtained through quality inspection. Inspection results have to be compromised between accuracy and measurement time [8].

Quality inspection has many definitions. For the purpose of this paper, it is defined as the verification of the manufacturing process or product for compliance with the requirements of internal or external customers. Quality check is usually carried out through direct measurement or visual inspection, and provides data for interpretation of the condition of the manufacturing process or product. Therefore, the data should be a reliable source of information (utility of a quality control system can be assessed with the use of methods and procedures of the statistical analysis of measurement and control systems [9]). The feature being assessed may be expressed in any measurement scale (depending on the organization of the manufacturing process and the customer requirements). The data collected may be precise (the so-called hard data) or imprecise, incomplete and/or unreliable (the so-called soft data [10-11]). The inspection methods used should depend on the character of the monitored product feature or process parameter.

There are numerous quality inspection methods. Developed since the 1920 s, they were initially constrained to the assessment of a finished product. Products which failed to meet certain requirements were discarded and returned to the manufacturing process or scrapped. Such an approach to quality control was criticised in the 1950s for generating high costs of repairs and scrapping to be incurred by the organization [12-15].

Subsequent decades brought the development of the process-based approach to manufacturing and the idea of "zero defects manufacturing". They both significantly changed the understanding of quality control. The underlying concept of the modern approach to quality control is that it should be carried out at selected (or even all) stages rather than at the end of the production process. The key objective of quality control is early detection of irregularities in the process and their causes, and application of corrective and preventive activities. Such an approach makes it possible to control the process quality and improves the opportunity to maintain the desired quality level [15].

The usual inspection method in repetitive manufacturing is the statistical inspection. Here, measurement of each produced unit is economically unjustified, and often technically impossible. An entire lot of products (the manufacturing process) is assessed on the basis of the results obtained from an analysis of a random sample.

Contrary to the statistical inspection, the 100 percent inspection method covers all the produced units. This method is time-consuming and applied only in unit or small series manufacturing. In series manufacturing, 100 percent quality inspection is implemented only in special cases, where the delivery of products incompliant with the requirements may have serious consequences [14, 16-17].

A vitally important aspect of quality inspection is planning. It should cover the definition of the objectives of quality control, time to carry out inspections, the inspected product features, methods of assessment, etc. First and foremost however, as a task which does not generate any added value, quality inspection should be justified in terms of the efficiency of the manufacturing process [18-19]. It should be noted here that even a perfectly planned and carried out quality inspection is not fully effective. Improper planning or poor organization of a quality inspection may generate waste of resources.

There are three types of quality inspection which are: incoming inspection, in-process inspection and final inspection [20]. This paper focuses on all of them - the paper presents the results of research related to the analysis of inspection operations in the process of manufacturing of the central venous catheter. 


\section{Problem statement}

The research aims at reducing the costs of quality control in the process of manufacturing of the catheter used for central venous pressure monitoring and blood sampling by the Seldinger technique. The catheter comes in a kit with a stainless steel guide wire and a needle. The Seldinger technique of central venous pressure monitoring and blood sampling requires placement of the catheter in a blood vessel by means of the needle. A cannula is inserted into the vessel and the guide wire advanced through the cannula. Once the cannula is retracted, the catheter is inserted in the place where the guide wire was introduced. Next, the guide wire is pulled out and the catheter is secured by means of a wing [21]. The catheter consists of four components (Fig. 1): a capillary with a wing, a formed (sharpened) tip, a connector tube, a valve.

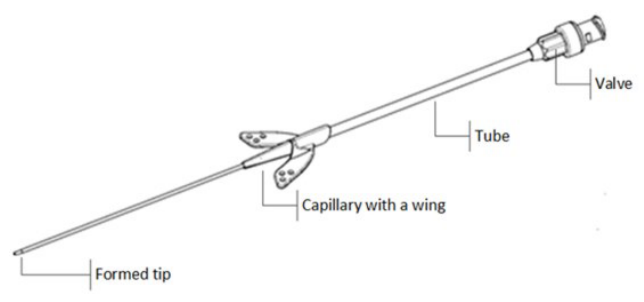

Fig. 1. The design of a diagnostic catheter.

The components of the catheter are connected in the process of bonding. The adhesive connections must be air/water tight and break proof. Considering the fact that leaks occurred in some of the products supplied to the customer in the past, the organization decided to implement additional inspections for air leaks in the manufacturing process. Moreover, following the introduction of certain alterations to the product design, an additional 100 percent acceptance inspection was implemented with respect to one of the components - the capillary with a wing.

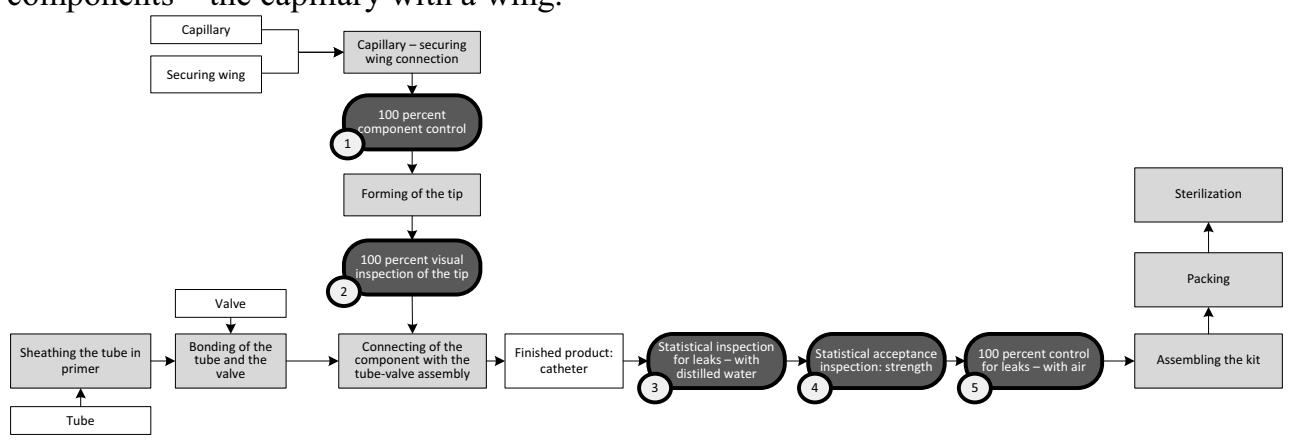

Fig. 2. Catheter manufacturing process map with control points.

In consequence, 5 inspections were implemented in the manufacturing process (Fig. 2):

- 100 percent component acceptance inspection - inspection of the diameter - nondestructive examination,

- 100 percent inspection of the edged tip - non-destructive examination,

- statistical inspection of adhesive connections for leaks, with the use of distilled water destructive examination,

- statistical acceptance inspection of adhesive connections for strength - destructive examination,

- 100 percent inspection of the catheter for air leaks - non-destructive examination. 
The implementation of additional inspections (Fig. 2 - control no. 1 and no. 3) made the manufacturing process more time-consuming and required the use of additional resources (material). After some time, the inspections were verified for validity.

\section{Improvement of inspections}

For several months, costs related to the inspections, as well as the efficiency and stability of the manufacturing process, were under analysis. The study was performed in five steps. The steps are described below, in an order corresponding to the numbering of inspections in Fig. 3. To improve inspection processes, DMAIC methodology was used [22].

\subsection{Component acceptance inspection}

The component acceptance inspection is a 100 percent inspection of the capillary bonded with the securing wing. The critical feature of the component is the diameter of the wing. A too large internal diameter of the wing opening is one of the reasons for leaks occurring in finished catheters. Twenty-two production batches of the component were examined to reveal that initially, the manufacturing process was characterised by a high percentage of incompliant products (in batch 2 , more than $23 \%$ of the components were incompliant) (Fig. 3). However, starting from batch 3 , the percentage of incompliant products diminished significantly. The mean percentage of incompliant products in the examined sample amounted to $1.09 \%$.

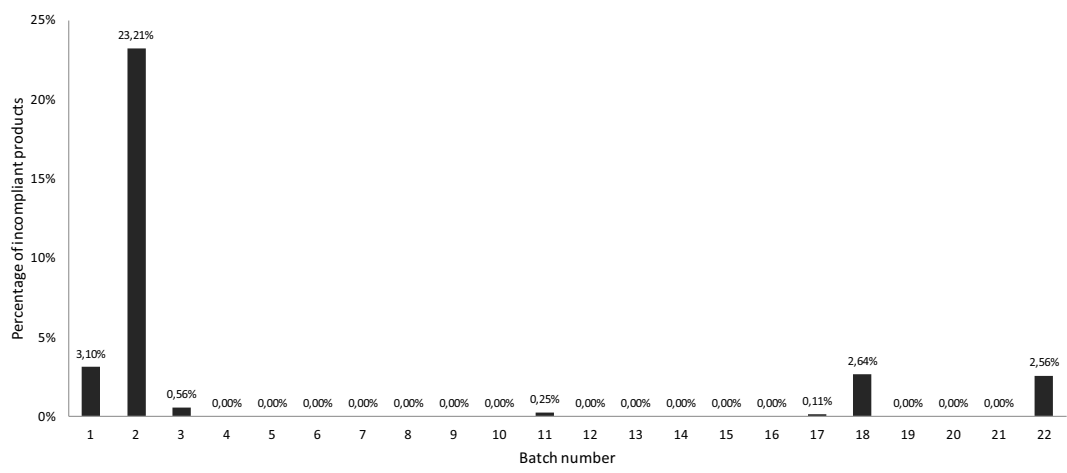

Fig. 3. Percentage of incompliant components (too large diameter) in analysed production batches (X axis - lot number, $\mathrm{Y}$ axis - percentage of incompliant components).

An analysis of the costs of inspection of the wing diameter in proportion to the total costs of manufacturing of the finished product revealed that the costs of inspection exceed the total costs of manufacturing of the catheter with a defective component by almost $25 \%$.

The results of the analysis show that it would be reasonable to skip the first inspection, even more so considering that catheters with this type of defect will be excluded at the 100 percent final inspection for leaks.

\subsection{Visual inspection of the catheter tip}

Similarly to the inspection for leaks, this visual inspection is a 100 percent control. The geometry and manufacturing precision of the catheter tip are examined under the microscope. Five or six catheters are examined at a time for scratches, cavities, grooves, pits or jagged spots on the surface.

The inspection is carried out following the operation of forming the catheter tip, and is 
indispensable. Its cost amounts to $120 \%$ of the total costs of technological operations for the finished product.

\subsection{Statistical inspection for leaks with distilled water}

The $3^{\text {rd }}$ type of inspection is the inspection for leaks with the use of distilled water. After contact with water, the catheter cannot be reused due to the risk of impurities in the water. Therefore, this type of destructive testing is carried out on a number of randomly selected catheters from a given lot.

The tested catheter is connected to the measuring device on one side. On the other side, a steel wire of an appropriate diameter is inserted and advanced to seal the measurement system. Next, distilled water is let into the system and pressure is monitored. Any drop of pressure indicates leaks in the catheter.

Considering that in the existing manufacturing process, the catheter was tested for leaks twice (inspection no. 3 and final inspection no. 5), the validity of the statistical inspection no. 3 was questioned (redundant destructive testing). Next, the effectiveness of the inspection for leaks with distilled water was verified against tests for leaks with air. In the first step, all catheters in the analysed lot were tested for leaks with air, and the leaking catheters were discarded. Next, the leaking catheters were tested again for leaks - with the use of distilled water. It turned out that in the process of testing with distilled water, only $35 \%$ of leaking catheters were detected. As a result, the researchers decided to skip the testing with distilled water due to its ineffectiveness.

\subsection{Statistical acceptance inspection - evaluation of adhesive connections for strength}

The $4^{\text {th }}$ inspection in the manufacturing process is the statistical inspection of lots of finished products. Here, catheters are tested for strength of the adhesive connections with the use of a breaking force (destructive testing). The tube in the catheter is cut into two in order to examine the adhesive connection between the valve and the tube, and between the tube and the wing. The breaking force cannot be smaller than $18 \mathrm{~N}$. According to the inspection plan, 8 to 20 items are tested, depending on the size of the lot. For example, for a lot of 260 items, 13 randomly selected catheters are tested. A lot is considered compliant with the requirements if none of the catheters is defective.

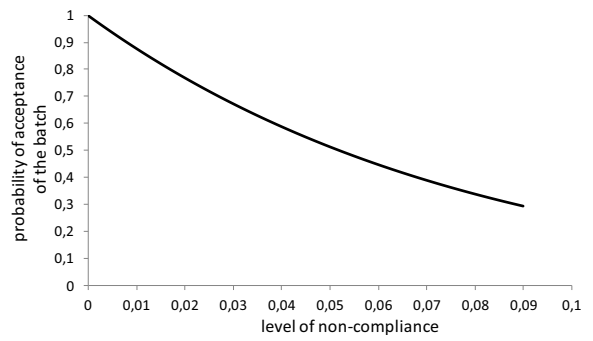

Fig. 4. The characteristic curve of the acceptance inspection plan for a sample of 13 items and $A c=0$.

It results from an analysis of the linear characteristic curve of the acceptance inspection plan for a sample of 13 items and the zero acceptance number $(\mathrm{Ac}=0)($ Fig. 4) that with the factual defectiveness of the process at $0.5 \%$, the probability that a lot is considered compliant equals $94 \%$. On the basis of the analysis results, the statistical acceptance inspection was considered inappropriate at this stage of the manufacturing process.

The downside of the discussed approach is that incompliance is detected only after the entire lot is produced. There is no possibility to discard the items where adhesive 
connections do not meet the strength requirements, because the testing is destructive. Therefore, a solution was proposed to monitor the strength of the adhesive connection during the manufacturing process, with the use of process control charts.

Mean value and range control charts were implemented for 13-item samples to monitor the valve-tube and wing-tube connections (Fig. 5). It results from an analysis of the graphs in Figure 6 and the performed calculations that the process is not stable, but shows a high capability in the short term. Further steps were taken to stabilize the process and optimise the size of the control sample.

a)

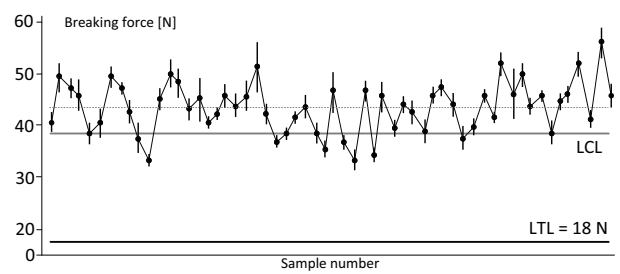

b)

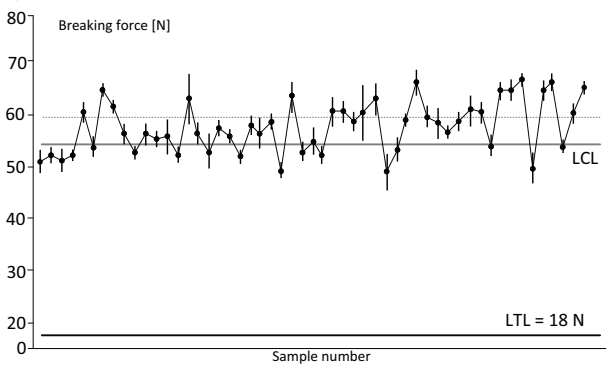

Fig. 5. Mean value chart for 13 -item samples for the valve-tube (a) and wing-tube (b) connections.

The sample size was reduced from 13 to 3 items. Figure 6 presents a control chart for the valve-tube connection for a 3-item sample. In Table 1, calculations of probability are presented for the results of individual adhesive force measurements below the lower tolerance line (LTL). The LTL is the process safety indicator. The standard deviation was determined with the Hartley formula for a 3-item sample.

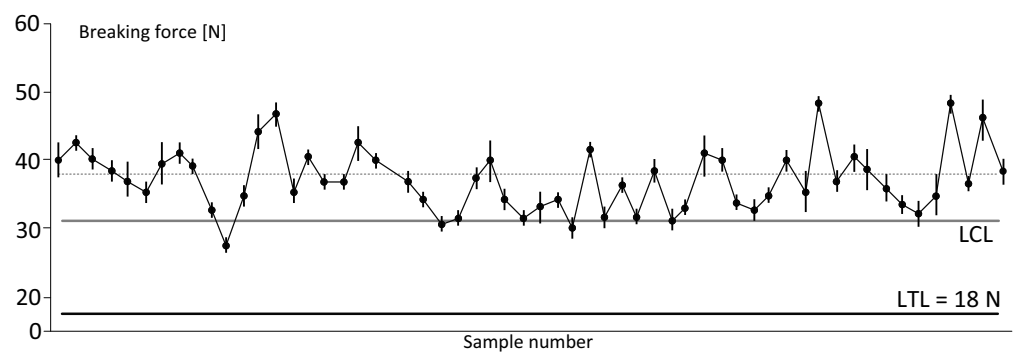

Fig. 6. Control chart for the valve-tube connection - 3-item sample.

Tab. 1. Probability of obtaining the adhesive force below the LTL for various values of the process mean deviation for the valve-tube and wing-tube connections (3-item samples).

\begin{tabular}{ccc}
\hline Mean process deviation & $\begin{array}{r}\text { Probability of obtaining the adhesive strength below the LTL } \\
\text { valve-tube }\end{array}$ & $\begin{array}{r}\text { wing-tube } \\
\text { (1) }\end{array}$ \\
\hline 2 & 0.0006227 & 0.0000000 \\
0.0129309 & 0.0000000 \\
0.1096711 & 0.0000001 \\
\hline
\end{tabular}

Owing to a high capability of both processes (1.41 for the valve-tube connection and 2.74 for the wing-tube connection), the chance of obtaining the adhesive force value below the LTL is very small, even at a significant deviation of the process mean. Further improvement of the process should aim at reducing its variability (stabilizing the process). 


\subsection{Inspection of adhesive connections for leaks - with compressed air}

The fifth inspection is carried out after the capillary is connected to the valve-tube assembly. It is a 100 percent control, which means that each item in the lot is examined. For this purpose, compressed air at a pressure of $800+5 \mathrm{mmHg}$ is let into the catheter. Next, the compressed air inlet is closed and the pressure is monitored by means of a pressure calibrator. The control of catheters for leaks is indispensable. Owing to the use of compressed air, the testing is non-destructive.

\section{Conclusions}

The research aimed to analyse and - if justified and possible - reduce the costs of quality control in the process of manufacturing of the catheter for central venous pressure monitoring and blood sampling by the Seldinger technique. The research was conducted for about a year. The resultant savings are presented in Table 2 .

Tab. 2. Quality control costs in the manufacturing process of the diagnostic catheter - before and after the implementation of changes.

\begin{tabular}{lcc}
\hline \multicolumn{1}{c}{$\begin{array}{c}\text { Quality control cost items - manufacturing of the } \\
\text { diagnostic catheter }\end{array}$} & $\begin{array}{c}\text { Control value } \\
\text { (percentage) }\end{array}$ & Savings \\
\hline A. 100 percent inspection - total cost & $60.75 \%$ & reduced by $1.53 \%$ \\
Visual inspection of the tip & $6.35 \%$ & no change \\
Inspection for leaks (with compressed air) & $47.49 \%$ & no change \\
Component acceptance inspection & $6.91 \%$ & reduced by $1.53 \%$ \\
B. Statistical destructive testing - total cost & $39.25 \%$ & reduced by $31.98 \%$ \\
inspection for leaks (with distilled water) & $4.26 \%$ & reduced by $4.26 \%$ \\
Inspection of adhesive connections for strength & $7.10 \%$ & $6.29 \%$ \\
Catheter (sample) manufacturing costs) & $27.89 \%$ & $21.44 \%$ \\
C. Total control costs & $100.00 \%$ & $33.51 \%$ \\
\hline Total savings & \multicolumn{2}{|c|}{$\mathbf{3 3 . 5 1 \%}$} \\
\hline "Savings after the implementation of changes - in percentage value, in proportion to the total control cost (C).
\end{tabular}

To sum up, the works covered the identification and research of control tasks. The inspections were analysed and actions were proposed for each control task (skipping the control task or implementation of improvement actions). Inspection no. 1 was proven to be economically unjustified and eliminated from the manufacturing process. Likewise, inspection no. 3 (tests for leaks with the use of distilled water) was found ineffective and unjustified, considering the fact that the next stage of the manufacturing process included a 100 percent control of air/water tightness with the use of air.

Therefore, in order to reduce the total control cost, skipping of inspection no. 3 was proposed. Inspection no. 4 (statistical acceptance inspection) was found to be inappropriate at that stage of the manufacturing process. Instead, as a result of the research, the use of mean value and range control charts was suggested. Moreover, the sample size was reduced from 13 to 3 items. As a result of the research, the total cost of quality control in the manufacturing process of the diagnostic catheter was reduced by more than $33 \%$.

The results presented in the paper come from a scientific statutory research conducted at the Chair of Management and Production Engineering, Faculty of Mechanical Engineering and Management, Poznan University of Technology, Poland, supported by the Polish Ministry of Science and Higher Education from the financial means in 2017: 02/23/DSPB/7695. 


\section{References}

1. A. Lewandowska, E. Więcek-Janka, $3^{\text {rd }}$ Int. Conf. on Man. Sc. and Man. Inn. (MSMI 2016), AEBMR-Adv. in Econ. Bus. and Man. Res., Atlantis Press, 10, 219 (2016)

2. J. Trojanowska, E. Pająk, $7^{\text {th }}$ International Conference of DAAAM Baltic Industrial Engineering,Tallin, Estonia, 1, 322 (2010)

3. J. Trojanowska, K. Żywicki, E. Pająk, Information Technologies in Environmental Engineering, Springer, 695 (2011)

4. K. Kalinowski, M. Zemczak, Adv. in Intelligent Systems and Computing, Springer, 368, 475 (2015)

5. M. Jasiulewicz-Kaczmarek, IFAC Conf. on Manufacturing Modelling, Management and Control (MIM), (IFAC Papers On Line, 49 (12), 674, 2016)

6. R. Dylewski, A. Jardzioch, I. Krebs, Man. and Prod. Eng. Rev., 7 (4), 97 (2016)

7. S. Kłos, Com. In Comp. and Inf. Sc., 639, 42 (2016)

8. S.H. Mian, A. Al-Ahmari, Pi. Mech. Eng. B-J Eng., 231 (4), 565 (2017)

9. M. Diering, K. Dyczkowski, Proc. IEEE Int. Conf. on Industrial Engineering and Engineering Management, 228 (2016)

10. A. Stachowiak, K. Dyczkowski, Proc. IFSA World Cong. and NAFIPS, IEEE, 390 (2013)

11. E. Więcek-Janka, R. Mierzwiak, Grey Sys.: Th. and Appl., 5 (3), 302 (2015)

12. C.G. Drury, M.A. Sinclair, Hum Factors Ergon Manuf, 25 (4), 391 (1983)

13. A. Hamrol, D. Kowalik, A. Kujawińska,, Hum. factors ergon. manuf., 21 (2), 156 (2011)

14. M. Rogalewicz, R. Sika, Man. and Prod. Eng. Rev., 7 (4), 97 (2016)

15. A. Hamrol, Prod. Plan. Control, 11 (8), 797 (2000)

16. A. Kujawińska, K. Vogt, F. Wachowiak, Technology Management for Sustainable Production and Logistics, (EcoProduction, Springer, 193, 2015)

17. A. Kujawińska, A. Vogt, A. Hamrol, Advances in Intelligent Systems and Computing, HAAMAHA, 490, 569 (2016)

18. B. Skołud, D. Krenczyk, $4^{\text {th }}$ Int. Scientific-Technical Conf. MANUFACTURING, in: Selected Conf. Proc. (Poznan University of Technology, December 2014, 35, 2016)

19. M. Suszyński, J. Żurek, S. Legutko, Tehnicki Vjesnik/Technical Gazette, 21 (6), 1229 (2014)

20. Y. Ngadiman, B. Hussin, A.T. Bon, N.A.A. Hamid, ICMME 2016, MATEC Web Conf., 95:10007 (2017)

21. Z.C.J. Higgs, D.A.L. Macafee, B.D. Braithwaite, C.A. Maxwell-Armstrong, The Seldinger technique: 50 years on, Lancet, 366 (9494), 1407 (2005)

22. S. Mahato, A.R. Dixit, R. Agrawal, J. of Eng. Manufacture, 231 (4), 713 (2017) 